\title{
Influence of Adaptive Statistical Iterative Reconstruction (ASIR) algorithm on Dose Reduction and Image Quality in CT Chest with contrast Examination compared with the FBP techniques
}

Isam, M..$^{1 *}$; Mokhtar, A. ${ }^{2}$; Abdelrazek, A. ${ }^{1}$; EL Mogy, S. ${ }^{3}$ and Oraby, A.H. ${ }^{1}$

Received: 01/07/2018

Accepted: 19/07/2018

E.mail:me.abdelhameed@gmail.com

\section{KEYWORDS}

ASIR; FBP; CNR;

$S N R ; B M I ; D L P$.

\section{ABSTRACT}

Presented study aims to estimate the influence of Adaptive Statistical Iterative Reconstruction (ASIR) algorithm on dose reduction and images quality on Computed tomography (CT) Chest with contrast examination compared with the traditional Filter back projection techniques (FBP). Patients were performed by two scanner using two reconstruction techniques, FBP in 28 patients and ASIR algorithm in 22 patients. Signal-to-Noise Ratio (SNR) and Contrast-to-Noise Ratio (CNR) were compared between FBP and ASIR images, CT images were tested on different percentage ASIR $(0 \%, 30 \%, 50 \%$, and $80 \%$ ). Then, FBP and ASIR images were compared again. Computed tomography dose index volume $\left(\mathrm{CTDI}_{\mathrm{voL}}\right)$ and effective doses (EDs) recorded simultaneously. Images quality parameters were estimated at the level of the carina in the descending thoracic aorta. Resulting data assessed by two techniques (FBP, ASIR) were compared statistically. The average image quality in FBP was superior to that of ASIR images. SNR were $(16.50 \pm 5.91,7.58 \pm 0.81 \mathrm{BMI}<30)(12.78 \pm 8.63$, $8.37 \pm 3.51$, BMI $>30)$, CNR were $(11.88 \pm 5.60,5.35 \pm 0.94$, BMI $<30)$, $(8.85 \pm 7.60,5.39 \pm 2.72, \mathrm{BMI}>30)$ for FBP, ASIR respectively. Significant increase in the SNR and CNR was observed with increased percentage of ASIR. ASIR had a statistically significantly $(\mathrm{P}=0.048)$ lower $\mathrm{CTDI}_{\mathrm{vol}}(9.57 \pm 1.08)$ than the conventional FBP (13.71 \pm 3.45$)$, with the use of ASIR, ED were slight differ compared with FBP, the

1. Physics Department, Faculty of Science, Mansoura University, Egypt.

2. Radiology Department, Nephrology and Urology Center, Mansoura University, Egypt.

3. Radiology Department, Faculty of Medicine, Mansoura University, Egypt. 
ED values were $(7.53 \pm 1.37$, to $6.42 \pm 1.12$, BMI < $\left.30 \mathrm{~kg} / \mathrm{m}^{2}\right),(7.38 \pm 1.21$, to $7.99 \pm 2.42$ with BMI $\geq 30$ $\mathrm{kg} / \mathrm{m}^{2}$ ) for FBP, ASIR respectively. ASIR help in significantly improving image quality and decreasing radiation dose. More clinical evaluations are required to confirm the radiation dose decreasing potential with ASIR compared to conventional FBP reconstruction techniques.

\section{INTRODUCTION}

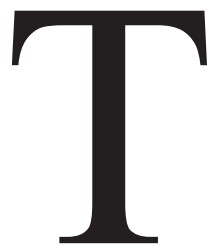

here are increasing concern about the magnitude of computed tomographic $(\mathrm{CT})$ radiation dose and the potential increase in incidence of radiation-induced carcinogenesis.

The lifetime cancer hazard depend on present $\mathrm{CT}$ usage has been predestined to be as high as $2.0 \%$ (Brenner and Hall, 2007).

CT scans are associated with higher patient doses as compared to other radiological examinations. In European and US hospitals the CT examinations account for more than $50 \%$ of the collective effective dose associated with medical exposure (Mayo et al., 2007; Martinsen et al., 2008). In 2002, 65\% of the total population radiation exposure in Norway was related to CT examinations increasing to $80 \%$ in 2008 . In Norway, CT examinations give rise to $59 \%$ of the total radiation dose associated with radiological examinations, but account for only $14 \%$ of the total X-ray examinations (Friberg et al., 2005). The European legislation demands that member states pay special attention to radiation protection in computed tomography and optimizing the CT examinations with respect to both radiation dose and image quality is mandatory in Norway (Wormanns et al., 2005).

In recent years, there has been increasing focus in the radiology community on reducing patients' X-ray radiation exposure. Correspond- ingly, one key focus of research and development among CT system manufacturers has been on techniques to maintain or improve image quality and diagnostic efficacy while reducing patient radiation dose. Different strategies for image quality and $\mathrm{CT}$ radiation dose optimization have been introduced: automatic current selection, bismuth shielding of breast tissue, thyroid gland and the lenses of the eyes, dose-reduction software, use of different reconstruction filters and iterative reconstruction (Brenner, 2004; Børretzen et al., 2006).

The standard CT reconstruction algorithm filtered back projection (FBP), miss ability to create images which have diagnostic quality with reduced X-ray tube currents (mA). Because image noise is increased by inherent in lowering the $\mathrm{CT}$ radiation dose, useful dose depression techniques decrease the effect of reduced dose on noise.

While, new reconstruction technique, Adaptive iterative reconstruction basically decreases image quantum noise with no impact on spatial or contrast resolution (Den Harder et al., 2015; Padole, 2015; Den Harder et al., 2016; Leipsic et al., 2016). This degree of substantial noise reduction can be taken as either improved image quality or as a reduction of patient radiation dose, typically in the $25-40 \%$ range compared to FBP. There are now over 5,000 CT systems operating world-wide with this technology. The process is repeated in successive iterative steps until the final estimated and ideal pixel values ultimately converge. By using this method, ASIR can identify and selectively reduce noise from an image (Alvin et al., 2010).

The goal of present study was to estimate the effect of Adaptive Statistical Iterative Reconstruction (ASIR) algorithm on Dose and Image Quality CT Chest with contrast Examination compared with the FBP techniques. 


\section{MATERIALS AND METHODS}

\section{Patient classification}

The study included 50 patients who underwent CT chest with contrast-enhanced examinations. These scans were done at (MANSOURA ADVANCED RADIOLOGY CENTER) Mansoura city, Egypt.

The patients were divided into two main groups (Group X) and (Group Y). Group X: 28 patients have been scanned on the CT scanner (BrightSpeed, GE Healthcare 8 detectors-USA) and reconstructed us- ing the FBP technique (Group $\mathrm{X}$ age range 20-79 years; mean age, 48.71years;gender 8 men and 20 women). Group Y: 22 patients have been scanned on the CT scanner (Revolution EVO, GE Healthcare 128 detectors, USA ) and reconstructed using ASIR technique $(10 \%$ to $100 \%$ ASIR in $10 \%$ increments) (Group Y age range, 33-85 years; mean age, 48.18 years; 12 men and 10 women). The all patient under the study were scanned with contrast-enhanced. The data of patient demographic were collected from the booking request forms, and body mass index (BMI) was calculated and presented in Table (1).

Table (1) : Patient CT demographic data.

\begin{tabular}{|c|c|c|c|c|c|c|}
\hline \multirow{2}{*}{$\begin{array}{c}\text { Variables } \\
\text { (with contrast) }\end{array}$} & \multicolumn{2}{|c|}{$\begin{array}{c}\text { FBP } \\
(n=28)\end{array}$} & \multicolumn{2}{|c|}{$\begin{array}{c}\text { ASIR } \\
(\mathrm{n}=22)\end{array}$} & \multirow{2}{*}{$\begin{array}{c}\text { Test of } \\
\text { significance }\end{array}$} & \multirow[t]{2}{*}{ p-value } \\
\hline & No & $\%$ & No & $\%$ & & \\
\hline $\begin{array}{l}\text { Gender } \\
\text { Male } \\
\text { Female }\end{array}$ & $\begin{array}{c}8 \\
20\end{array}$ & $\begin{array}{l}28.6 \\
71.4\end{array}$ & $\begin{array}{l}12 \\
10\end{array}$ & $\begin{array}{l}54.5 \\
45.5\end{array}$ & $\chi^{2}=1.73$ & 0.188 \\
\hline $\begin{array}{c}\text { Age/years } \\
\text { Mean } \pm \text { SD } \\
\text { Min-Max }\end{array}$ & \multicolumn{2}{|c|}{$\begin{array}{c}48.71 \pm 18.31 \\
20-79\end{array}$} & \multicolumn{2}{|c|}{$\begin{array}{c}48.18 \pm 14.85 \\
33-85\end{array}$} & $\mathrm{t}=0.078$ & 0.938 \\
\hline $\begin{array}{c}\text { BMI post } \\
\text { Mean } \pm \text { SD } \\
\text { Min-Max }\end{array}$ & \multicolumn{2}{|c|}{$\begin{array}{c}32.73 \pm 8.44 \\
22.04-52.08\end{array}$} & \multicolumn{2}{|c|}{$\begin{array}{c}34.19 \pm 7.73 \\
25.25-48.90\end{array}$} & $\mathrm{t}=0.447$ & 0.659 \\
\hline
\end{tabular}

\section{CT data acquisition}

The scanning range for the all patients on both of the two scanners was from supraclavicular space to the upper abdomen, including the bilateral adrenals gland. A mechanical injector (StellantH; Medrad, Warrendale, PA) was used for the intravenous bolus injection of non-ionic contrast material (iohexol) with a concentration of $300 \mathrm{mgml} 21$ iodine. $60-70 \mathrm{ml}$ of contrast material was injected at a flow rate of $2.5 \mathrm{ml} \mathrm{s} 21$ and a fixed start delay of $30 \mathrm{~s}$. The two CT scanners parameters protocols are shown in Table 2.
The needs of ASIR tuning requires picking of noise dispersion step of $10 \%$ in the full range. Such scale allow mixing of both FBP with ASIR routes for different noise depressions in the reconstructed images to attain the final reconstructed images based on the fixed scale of ASIR. For a noise depression (30\%), the data set of mixed reconstructed images belong to $70 \%$ FBP combined with $30 \%$ ASIR with extremely low image noise. 
Table (2) : Scanning protocols for Brightspeed (FBP) and Revolution EVO (ASIR) techniques.

\begin{tabular}{|c|c|c|}
\hline Scanning parameter & Brightspeed (FBP) & Revolution EVO (ASIR) \\
\hline Scan type & Helical(Spiral) & Helical \\
\hline Rotation time & $0.8 \mathrm{~s}$ & $0.6 \mathrm{~s}$ \\
\hline Detector row & 8 & 128 \\
\hline Slice thickness & $2.5 \mathrm{~mm}$ & $2.5 \mathrm{~mm}$ \\
\hline Beam collimation & $20 \mathrm{~mm}$ & $91.66 \mathrm{~mm}$ \\
\hline Pitch & $1.35: 1$ & $1.373 / 1$ \\
\hline Speed & $27 \mathrm{~mm} / \mathrm{rot}$ & $55 \mathrm{~mm} / \mathrm{rot}$ \\
\hline S FOV & large $50 \mathrm{~cm}$ & Large $50 \mathrm{~cm}$ \\
\hline KVP & 120 & 120 \\
\hline Auto $\mathrm{mA}$ & $200-250$ & $100-500$ \\
\hline recon 1 & Standard & standard \\
\hline recon 2 & Lung & Lung \\
\hline
\end{tabular}

\section{Image Quality}

Together subjective and objective images eminence estimations of the $50 \mathrm{CT}$ chest examination data were completed on the image communicating and archiving systems (PACS) indicative workstation. Noise extents obtained by patients CT image through introducing a $2.0 \mathrm{~cm}^{2}$ circular area in front of measurement region at the center of sloping thoracic aorta (homogeneous soft tissue ) while both standard deviation (SD) and mean values were verified and inferred to signal and the SD to a noise.

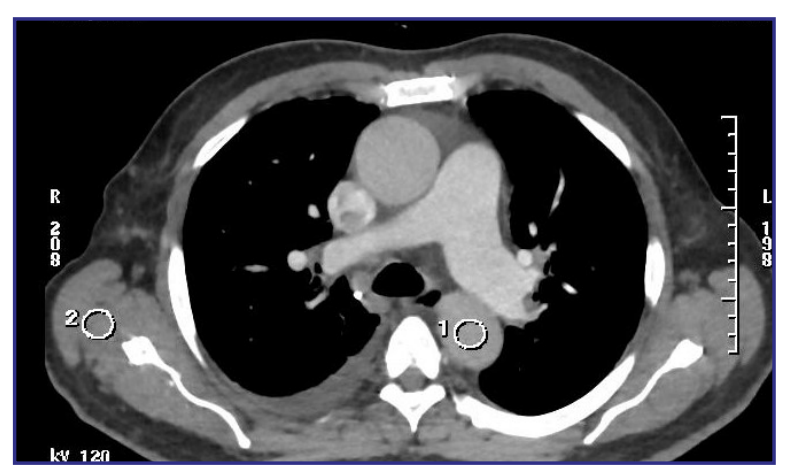

Fig. (1): The method of placing a region of interest $2.0 \mathrm{~cm}^{2}$ in the centre of the descending thoracic aorta at the level of carina in the mediastinal image.
Both contrast-to-noise ratio (CNR) and signal-to-noise ratio (SNR) were determined using Szucs-Farkas et al. method described elsewhere (Szucs-Farkas et al., 2009).

\section{Radiation Dose}

To estimate dose parameters for the 50 chest CT examination data reconstructed using ASIR or FBP technique such as, CT dose index volume $\left(\mathrm{CTDI}_{\mathrm{vol}}\right)$ and dose length product (DLP) were estimated for all patients from the dose report. Effective dose in millisieverts (EDs) was calculated by multiplying dose-length product $\times$ thoracic conversion $\mathrm{K}$ factor of $0.017 \mathrm{mSv} \mathrm{mGy}^{-1} \mathrm{~cm}^{-}$ as described in the EUR16262 document (EUR 16262, 2008).

\section{Statistical analysis}

Both of the two patients groups $\mathrm{X}$ and $\mathrm{Y}$ were also divided into two subgroups based on the Body Mass Index (BMI) (less than $30 \mathrm{~kg} / \mathrm{m}^{2}$, and $30 \mathrm{~kg} / \mathrm{m}^{2}$ or more). Data were analyzed with standard statistical software (SPSS version 21. The normality of data was first tested with Shapiro test. 
The paired Student's t-test was used to compare two techniques, image quality (signal-to-noise ratio (SNR), contras-to-noise ratio (CNR)) and doses $\left(\mathrm{CTDI}_{\mathrm{vol}}\right.$, DLP, EDs). It was of interest to determine if image quality, CNR, SNR, ratio of interpretable segments, or survey quality by the Likert scale differed (LSD) by percentage of ASIR used in reconstruction $(0 \%, 30 \%, 50 \%$, $80 \%$ ). In addition Qualitative data were characterized using number and percent. Association between categorical variables was tested using Chi-square test. Persistent variables were given as mean $\pm \mathrm{SD}$ (standard deviation). Repeated measured ANOVA was used to compare means in different doses. Pearson correlation was used to correlate continuous data The smaller the p-value obtained, the more significant are the results, $\mathrm{p}<0.05$ was treated statistically considerable.

\section{RESULTS}

Imaging was completed on 50 patients; ASIR was used in 22 cases and FBP alone in 28. Pa- tients demographic data are presented in Table [1] No considerable variation $(p>0.05)$ between the two techniques was found with respect to sex, age, BMI.

\section{Image quality}

Helical CT chest examination SNR and CNR values are listed in Table (3) as well as Figure $(2,3)$. The average image quality in FBP was superior to that of ASIR images. For BMI less than $30 \mathrm{Kg} / \mathrm{m}^{2} \mathrm{SNR}$ were $16.50 \pm 5.91,7.58 \pm 0.81$ for FBP, ASIR respectively and there is significant variation $(\mathrm{p}=0.017)$, and $\mathrm{CNR}$ were $11.88 \pm 5.60$, $5.35 \pm 0.94$ for FBP, ASIR respectively and there is significant variation $(\mathrm{P}=0.05)$, Figure (2).

For BMI more than $30 \mathrm{Kg} / \mathrm{m}^{2}$ SNR $12.78 \pm 8.63$, $8.37 \pm 3.51$ for FBP, ASIR respectively and there is no significant variation $(\mathrm{p}=0.234)$, and $\mathrm{CNR}$ were $8.85 \pm 7.60,5.39 \pm 2.72$ for FBP, ASIR respectively and the results showed insignificant variation $(\mathrm{P}=0.279)$, Figure (3).

Table (3) : Comparison of SNR, CNR using FBP, FBP-ASIR techniques.

\begin{tabular}{|c|c|c|c|c|c|}
\hline \multirow{2}{*}{ BMI } & CT parameters & FBP & ASIR & t-test & p-value \\
\hline \multirow{2}{*}{$<30$} & SNR & $16.50 \pm 5.91$ & $7.58 \pm 0.81$ & 2.93 & $0.017^{*}$ \\
\cline { 2 - 6 } & CNR & $11.88 \pm 5.60$ & $5.35 \pm 0.94$ & 2.26 & $0.05^{*}$ \\
\hline \multirow{2}{*}{$\geq 30$} & SNR & $12.78 \pm 8.63$ & $8.37 \pm 3.51$ & 1.25 & 0.234 \\
\cline { 2 - 6 } & CNR & $8.85 \pm 7.60$ & $5.39 \pm 2.72$ & 1.13 & 0.279 \\
\hline
\end{tabular}

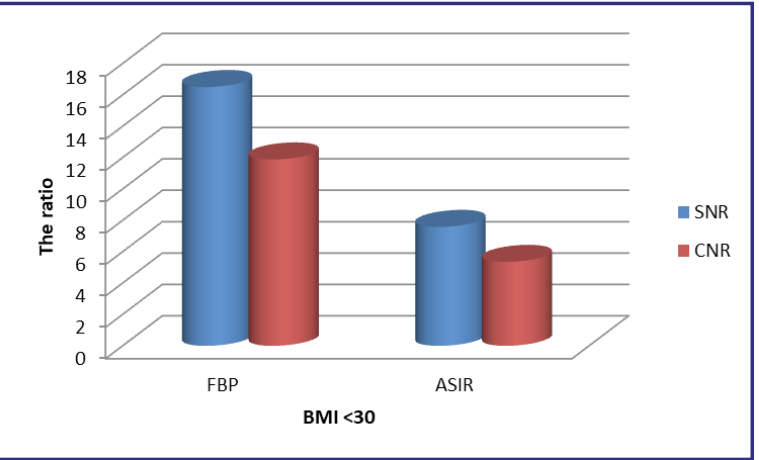

Fig. (2): Relation between SNR and CNR using FBP, ASIR technique for patients with $\mathrm{BMI}<30$.

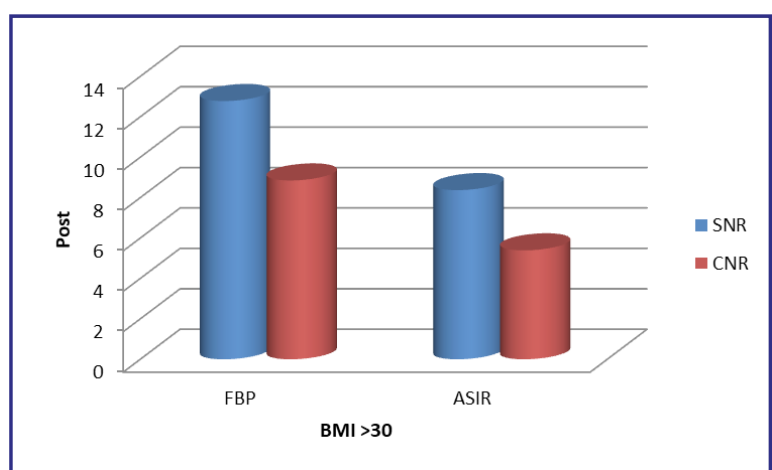

Fig. (3): Relation between SNR and CNR using FBP, ASIR technique for patient with $\mathrm{BMI}>30$. 
There was a significant increase in the SNR with increased percentage of ASIR (Table 4). SNR for spiral CT chest examination with BMI less than $30 \mathrm{Kg} / \mathrm{m}^{2}$, SNR was $7.57 \pm 0.81,9.81 \pm 0.87$, $4.56 \pm 2.08$, and $16.69 \pm 1.84$ for reconstructions with $0 \%, 30 \%, 50 \%$ and 80 ASIR respectively $(\mathrm{P}=0.007)$ and there was a significant increase in the CNR with $0 \%, 30 \%, 50 \%$ percentage of ASIR was $5.35 \pm 0.94,7.62 \pm 2.48,8.41 \pm 1.55$ respectively. But for $80 \%$ ASIR, CNR was a significant decrease

\subsection{9 \pm 1 , Figure (4).}

For BMI more than $30 \mathrm{Kg} / \mathrm{m}^{2}$ also SNR was increase $8.37 \pm 3.51,10.52 \pm 3.96,12.77 \pm 4.54$ and $17.12 \pm 5.84$ for reconstructions with $0 \%, 30 \%$, $50 \%$ and 80 ASIR respectively $(\mathrm{P}=0.01)$. CNR was increase $5.39 \pm 2.72,7.35 \pm 4.42,9.10 \pm 3.90$ for reconstructions with $0 \%, 30 \%, 50 \%$ respectively. But for $80 \%$ ASIR, CNR was decrease $8.05 \pm 5.30$, Figure (5).

Table (4) : SNR and CNR for CT chest examination at different percentage ASIR.

\begin{tabular}{|c|c|c|c|c|c|c|c|}
\hline \multirow{2}{*}{ BMI } & $\begin{array}{c}\text { CT } \\
\text { parameter }\end{array}$ & ASIR 0 & ASIR 30 & ASIR 50 & ASIR 80 & t-test & p-value \\
\hline \multirow{2}{*}{$<30$} & SNR & $7.57 \pm 0.81$ & $9.81 \pm 0.87$ & $11.85 \pm 0.97$ & $16.69 \pm 1.84$ & 41.87 & $<0.001^{* *}$ \\
\cline { 2 - 8 } & CNR & $5.35 \pm 0.94$ & $7.62 \pm 2.48$ & $8.41 \pm 1.55$ & $3.19 \pm 1.31$ & 7.94 & $0.003^{*}$ \\
\hline \multirow{2}{*}{$\geq 30$} & SNR & $8.37 \pm 3.51$ & $10.52 \pm 3.96$ & $12.77 \pm 4.54$ & $17.12 \pm 5.84$ & 4.72 & $0.01^{*}$ \\
\cline { 2 - 8 } & CNR & $5.39 \pm 2.72$ & $7.35 \pm 4.42$ & $9.10 \pm 3.90$ & $8.05 \pm 5.30$ & 0.97 & 0.422 \\
\hline
\end{tabular}

An increased percentage of ASIR was associated a linear improvement in SNR and CNR (Fig. 2, 3).

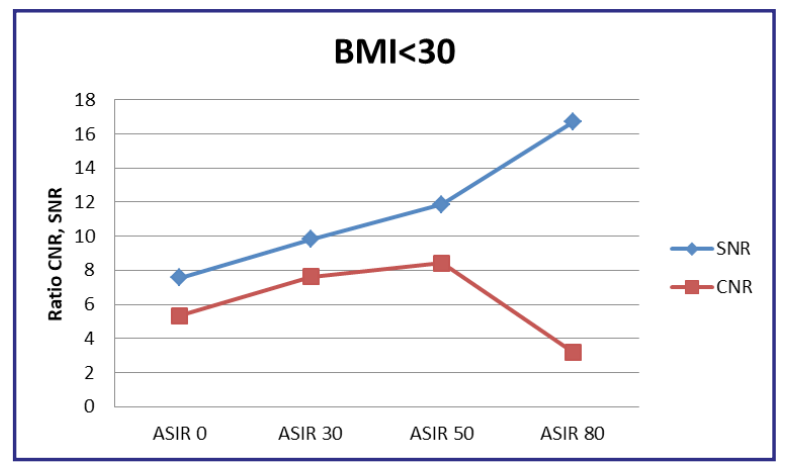

Fig. (4): Relation between different percentages of SIR, SNR and CNR in the group of $\mathrm{BMI}<30$.

\section{Radiation Dose}

Comparison of $\mathrm{CTDI}_{\mathrm{vOL}}$, EDs using FBP and ASIR techniques showed in (Table 5). ASIR had a statistically significantly $(\mathrm{P}=0.048)$ lower CTDIvol (9.57 \pm 1.08$)$ than the conventional FBP $(13.71 \pm 3.45)$, For BMI $<30$.

EDs were slight differ compared with FBP. EDs were range from $7.53 \pm 1.37$, to $6.42 \pm 1.12$ with BMI $<30 \mathrm{~kg} / \mathrm{m} 2$ ), and were varied from

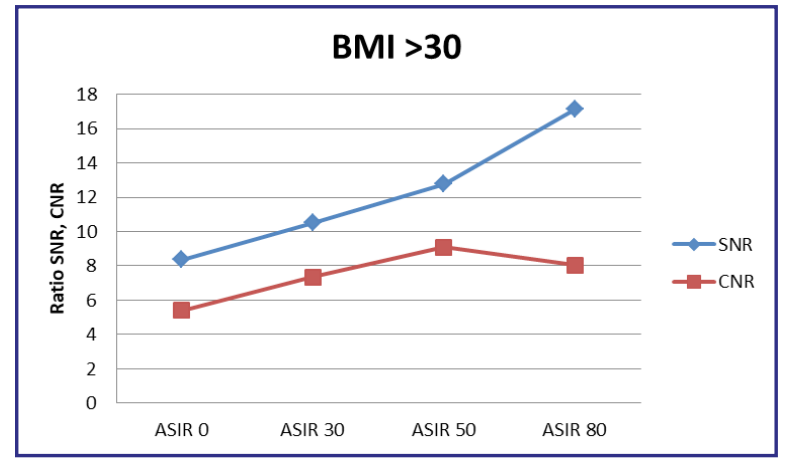

Fig. (5): Relation between different percentages of ASIR, SNR and CNR in the group of BMI $>30$.

$7.38 \pm 1.21$, to $7.99 \pm 2.42$ with $\mathrm{BMI} \geq 30 \mathrm{~kg} / \mathrm{m} 2$ for FBP, ASIR respectively. Statistically, there were no considerable variation $(\mathrm{P}=0.206$ and $\mathrm{P}=0.560$ respectively) noted.

The noise index (NI) is a descriptor for user coveted image noise scale for the CT examinations. There was a reciprocal relationship between radiation dose and NI, radiation dose was depressed by rising the NI Figure (6) and (7). 
Table (5) : CT dose index volume (CTDI ${ }_{\text {vol }}$, effective dose (ED) of FBP and ASIR.

\begin{tabular}{|c|c|c|c|c|c|}
\hline \multirow{2}{*}{ BMI } & Post & FBP & ASIR & t-test & p-value \\
\hline \multirow{2}{*}{$<30$} & CT DI & $13.71 \pm 3.45$ & $9.57 \pm 1.08$ & 2.28 & $0.048^{*}$ \\
\cline { 2 - 6 } & E & $7.53 \pm 1.37$ & $6.42 \pm 1.12$ & 1.36 & 0.206 \\
\hline \multirow{2}{*}{$\geq 30$} & CT DI & $13.75 \pm 3.25$ & $12.69 \pm 3.04$ & 0.627 & 0.542 \\
\cline { 2 - 6 } & E & $7.38 \pm 1.21$ & $7.99 \pm 2.42$ & 0.599 & 0.560 \\
\hline
\end{tabular}

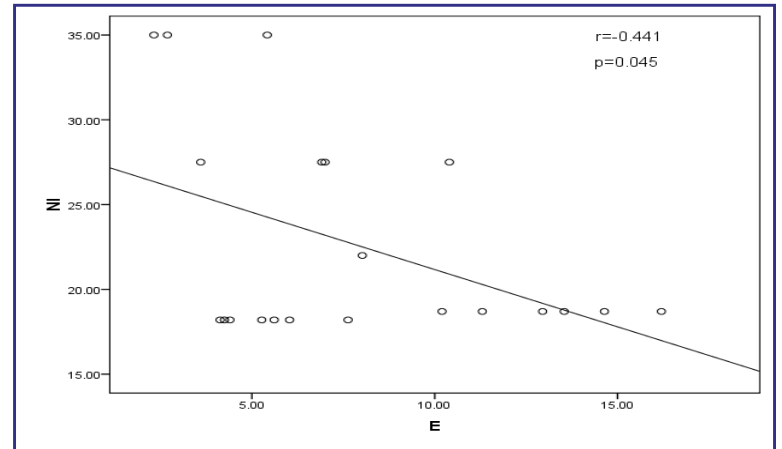

Fig. (6): Scatter diagram show correlation between EDs, $\mathrm{mSv}$ and NI by adaptive statistical iterative reconstruction (ASIR), Slopes of curve were significantly different $(\mathrm{P}=$ $0.045)$.
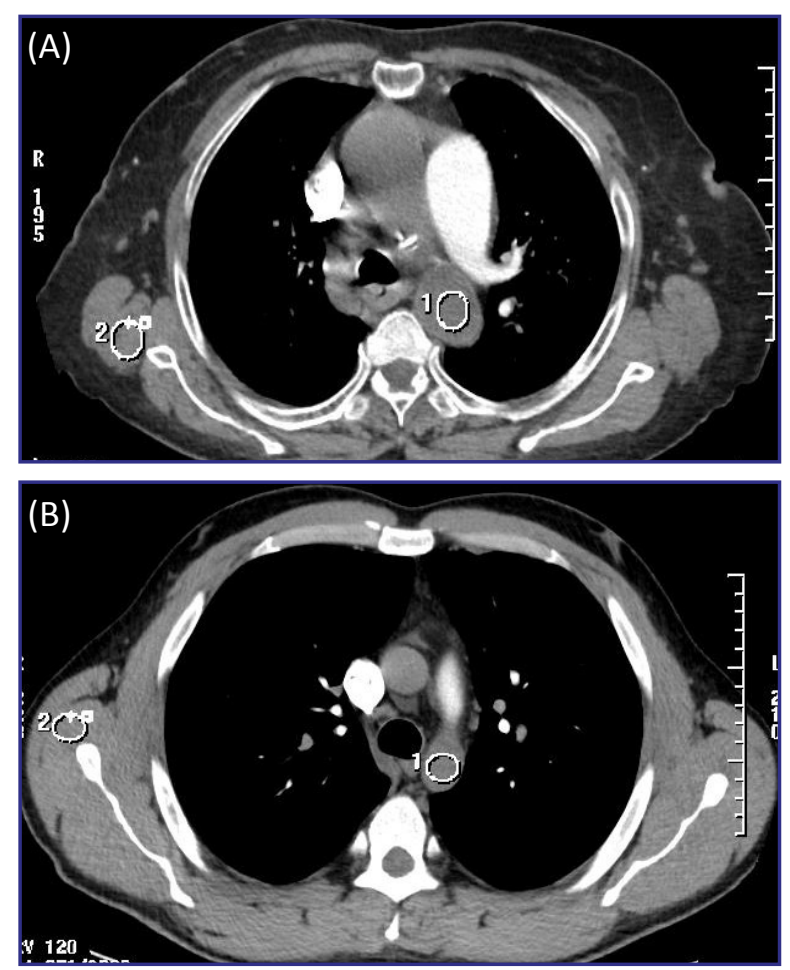

Fig. (7): Two axial CT chest images for two different patients with the same BMI $<30$. The NI and ED for the image (A) were 30 and 5.2 respectively but for image (B) were 25.3 and 8.9 respectively.

\section{DISCUSSION}

The main benefit of our study was to define the clinical influence of the ASIR technique on image quality and effective radiation dose in CT Chest with contrast-enhanced examination compared with the FBP techniques, we found that the average image quality in FBP was superior to that of ASIR images SNR were $16.50 \pm 5.91,7.58 \pm 0.81$ for FBP, ASIR respectively and there is significant variation $(\mathrm{p}=0.017)$, and $\mathrm{CNR}$ were $11.88 \pm 5.60,5.35 \pm 0.94$ for FBP, ASIR respectively and there is significant variation. While, many estimates shown significance of IR on the image quality of CT chest examination (Prakash et al, 2010; Yanagawa et al., 2010; Prakash et al., 2012). Pontana et al. (2011) found SNR ( $p<0.0001)$ and CNR $(p<0.0001)$ ratios were significantly increased with iterative reconstruction using a newly developed algorithm (iterative reconstruction in image space; IRIS) and this result disagree with our result.

ASIR uses more careful statistical design during the reconstruction process with the estimated signal is clear of noise due to x-ray photon statistics or electronic noise (Cheng et al., 2006). This enables increasing noise index, which decrease tube current and radiation dose. According to the study of Pontana et al, there is a direct relationship between the delivered dose and the image noise (when the radiation dose decreases, the image noise increases (Pontana et al., 2011). In our study, the increase percentage of ASIR resulted in significant noise reduction and improved SNR, 50\% and 80\% ASIR appeared to provide optimal image quality. and this result agree 
with (Leipsic et al., 2010), They concluded that ASIR permitted significant noise reduction in clinical coronary, using 40-60\% ASIR improved image quality in comparison with FBP

For CNR, there was a significant increase with $0 \%, 30 \%, 50 \%$ percentage of ASIR but for $80 \%$ ASIR, CNR was a significant decrease. The present findings suggest that imaging by using ASIR technique may be most favorable. It is interesting that there was a degradation of qualitative image quality using $80 \%$ ASIR, lower than that $50 \%$. Reconstructions with high proportions of ASIR are significantly different in appearance from $0 \%, 30 \%, 50 \%$ ASIR, with a different noise texture and significantly smoothed borders, which was described by one reader as a "plastic" appearance.

Several attempts to reduce radiation dose from CT have concentrated on improving techniques to decrease radiation dose while protecting or enhancing image quality and setting up the clinical value of low-radiation dose images for diagnostic information (Kalra et al., 2014). However, low-dose CT has higher image noise and can affect the diagnostic information, especially with conventional filtered back projection.

In this study, we found that ASIR had a statistically significantly $(\mathrm{P}=0.048)$ lower CT$\mathrm{DI}_{\mathrm{VOL}}(9.57 \pm 1.08)$ than the conventional FBP (13.71 \pm 3.45$)$. (Leipsic et al., 2010), found that CT$\mathrm{DI}_{\mathrm{VOL}}(15.4 \pm 6.38, \mathrm{FBP})$ and $(11.3 \pm 5, \mathrm{ASIR})$ with $\mathrm{P}$ $<0.0001$ and this result agree with our result.

Unfortunately, EDs were slight differ compared with FBP. EDs were range from $7.53 \pm 1.37$, to $6.42 \pm 1.12$ with $\mathrm{BMI}<30 \mathrm{~kg} / \mathrm{m} 2$ ), and were varied from $7.38 \pm 1.21$, to $7.99 \pm 2.42$ with $\mathrm{BMI} \geq$ $30 \mathrm{~kg} / \mathrm{m} 2$ for FBP, ASIR respectively. Statistically, there were no considerable variation $(\mathrm{P}=$ 0.206 and $\mathrm{P}=0.560$ respectively) noted. Although, Prakash et al. (2010) demonstrated that ASIR technique allows depression in radiation dose with chest
CT while decreasing image noise, ASIR allows dose depression by $26 \%$ to $29 \%$ compared with the FBP technique. L-P QI et al showed that, Radiation doses were significantly lower in the examinations that used ASIR (p, 0.001), Dose reduction by $27.7 \%$ to 71.8\% (QI et al., 2012). Our data support ASIR as an important first step in the use of iterative reconstruction techniques in $\mathrm{CT}$ chest with contrastenhanced examination.

There are restrictions in our study. Our study was obtained from various series of patients examined by two scanner using ASIR and FBP reconstructed techniques; However, there was no significant difference between patients' BMI. The ASIR reconstruction has not been fully utilized due to the absence of a fixed protocol for all technicians so that individual variation can be reduced.

\section{CONCLUSION}

The study shows that there was statistically no considerable difference in effective radiation doses associated with contrast CT scan of chest reconstructed with FBP or ASIR. The reason was due to absence of good trained technicians of the usefulness the ASIR technology and its ability to maintain the image quality with low dose.

Reconstruction ASIR technique as previous studies can improve image quality with low radiation dose. Further clinical evaluation is required to confirm that ASIR is considerable method to decrease dose with acceptable image for the diagnostic of disorders on our institute. For improving the image quality and management radiation dose reduction we recommend that medical physicist should be attended in radiology department.

\section{REFERENCES}

- Alvin, C.S.; Holly, J.L.; Amy, H.; Jennifer, K. and William, P. (2010): Innovations in CT Dose 
Influence of Adaptive Statistical Iterative Reconstruction (ASIR) algorithm on Dose Reduction and Image (175) Quality in CT Chest with contrast Examination compared with the FBP techniques

Reduction Strategy: Application of the Adaptive Statistical Iterative Reconstruction Algorithm. A.J.R, 194: 191 .

- Børretzen, I.; Lysdahl, K.B. and Olerud, H.M. (2006): Radiology in Norway - examination frequency per 2002, trends in time, geographical variation and population dose, Østerås, Norway: Norwegian Radiation Protection Authority.

- Brenner, D.J. and Hall, E.J. (2007): Computed tomography: an increasing source of radiation exposure. N. Engl. J. Med., 357: 2277.

- Brenner, D.J. (2004): Radiation risk potentially associated with low-dose CT screening of adult smokers for lung cancer. Radiology, 231(2): 440.

- Cheng, L.C.; Fang, T. and Tyan, J. (2015): Fast iterative adaptive reconstruction in low-dose CT imaging. Proceedings of the IEEE International Conference on Image Processing. New York, NY: IEEE, 889.

- Den Harder, A.M.; Willemink, M.J. and Ruiter, Q.M. (2015): Achievable dose reduction using iterative reconstruction for chest computed tomography: a systematic review, Europ. J. Radiol., 84: 2307.

- Den Harder, A.M.; Willemink, M.J. and Ruiter, Q.M. (2016): Dose reduction with iterative reconstruction for coronary CT angiography: a systematic review and meta-analysis, Brit. J. Radiol., 89: 20150068 .

- EUR 16262; (2008): Quality criteria for computed tomography, at: www.drs.dk/guidelines/ct/quality/ download/eur16262.w51.Accessed.

- Friberg, E.G.; Widmark, A.; Olerud, H.M.; Tynes, T. and Saxebøl, G. (2005): Guidance for use of medical X-ray and MR equipment subjected to approval. Guidance to "Regulations for radiation protection and use of radiation". Guidance No. 5, In Norwegian. Østerås: Norwegian Radiation Protection Authority.
- Leipsic, J.; Nguyen, G.; Brown, J.; Sin, D. and Mayo, J.R. (2010): A Prospective Evaluation of Dose Reduction and Image Quality in Chest CT Using Adaptive Statistical Iterative Reconstruction, AJR, 195: 1095.

- Kalra, M.K.; Maher, M.M. and Toth, T.L. (2004): Strategies for CT radiation dose optimization. Radiology, 230: 619Y628.

- Leipsic, J.L.; Heilbron, B.G. and Hague, C. (2012): Iterative reconstruction for coronary $\mathrm{CT}$ angiography: finding its way. Int. J. Cardiovasc. Imaging, 28: 613.

- Qi, L.P.; Li, Y.; Tang, L.; Li, Y-L. and Li, X-T. (2012): Evaluation of dose reduction and image quality in chest CT using adaptive statistical iterative reconstruction with the same group of patients. Br. J. Radiol., 85: e906.

- Martinsen, A.C.T.; Sæther, H.K.; Olsen, D.R.; Skaane, P. and Olerud, H.M. (2008): Reduction in dose from $\mathrm{CT}$ examinations of liver lesions with a new postprocessing filter: a ROC phantom study. Acta Radiol., 49(3): 303.

- Mayo, J.R.; Aldrich, J. and Müller, N.L. (2003): Radiation exposure at chest CT: a statement of the Fleischner Society. Radiology, 228(1): 15.

- Padole, A.; Ali, R.D. and Kalra, M. (2012): CT radiation dose and iterative reconstruction techniques, AJR, 204: W384.

- Pontana, F.; Duhamel, A. and Pagniez, J.; (2011): Chest computed tomography using iterative reconstruction vs. filtered back projection (part 2): image quality of low-dose CT examinations in 80 patients. Eur. Radiol., 21: 636.

- Prakash, P.; Kalra, M.K.; Ackman, J.B.; Digumarthy, S.R.; Hsieh, J. and Do, S. (2010): Diffuse lung disease: CT of the chest with adaptive statistical iterative reconstruction technique. Radiology, 256: 261. 
- Prakash, P.; Kalra, M.K.; Digumarthy, S.R.; Hsieh, J.; Pien, H. and Singh, S. (2010): Radiation dose reduction with chest computed tomography using adaptive statistical iterative reconstruction technique: initial experience. J. Comput. Assist. Tomogr., 34: 40.

- Szucs-Farkas, Z.; Strautz, T.; Patak, M.A. Kurmann, L.; Vock, P. and Schindera, S.T. (2009): Is body weight the most appropriate criterion to select patients eligible for low-dose pulmonary CT angiography? Analysis of objective and subjective image quality at $80 \mathrm{kVp}$ in 100 patients. Eur. Radiol., 19: 1914.
- Wormanns, D.; Ludwig, K.; Beyer, F.; Heindel, W. and Diederich, S. (2005): Detection of pulmonary nodules at multirow-detector CT: effectiveness of double reading to improve sensitivity at standard-dose and low-dose chest CT. Eur. Radiol., 15(1): 14 .

- Yanagawa, M.; Honda, O.; Yoshida, S.; Kikuyama, A.; Inoue, A. and Sumikawa, H. (2010): Adaptive statistical iterative reconstruction technique for pulmonary CT: image quality of the cadaveric lung on standard- and reduced-dose CT. Acad. Radiol., 17: 1259. 


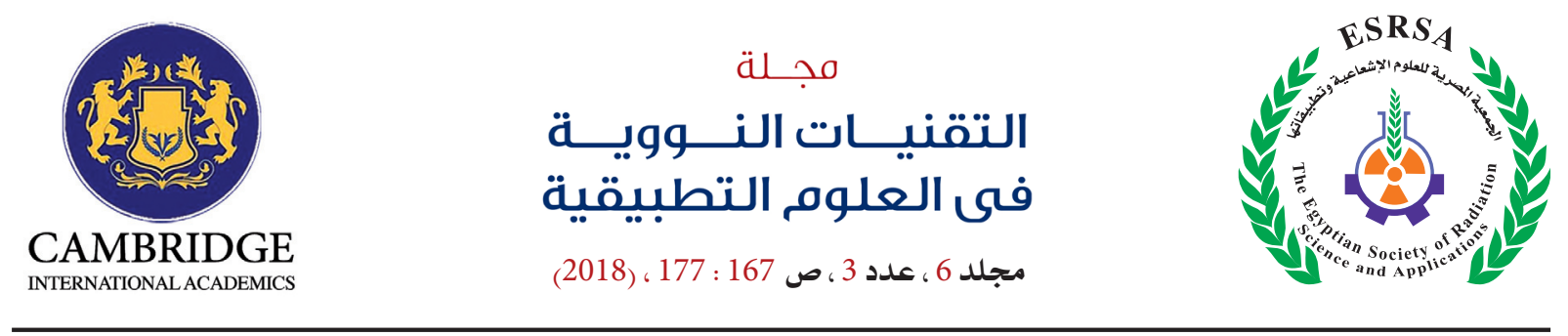

تأثير خوارزميت التكيف التكراري الإحصائيت التكراريت (ASIR) على خفض الجرايت الترعت

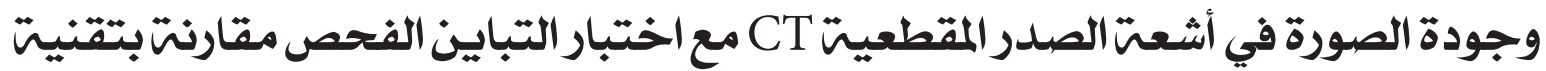
FBP الاسقاط الخلفي مريم عصام' وايمن مختار' وآيت عبدالرازق' وصبري الموجى' واحمد حمزه عرابي'

الدراست الحاليت تهدف الي تقدير تأثير تقنيه بناء الصوره التكرارى (ASIR) على جودة

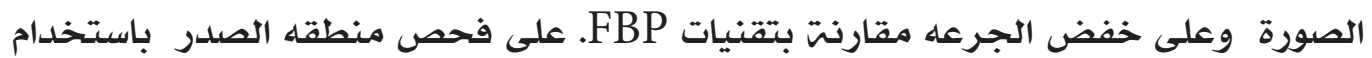

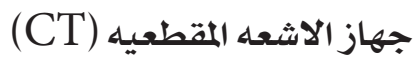

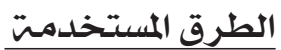

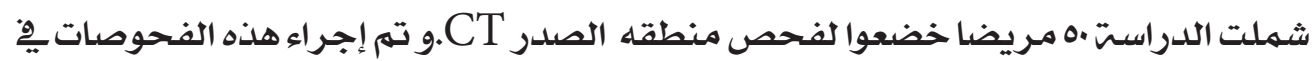

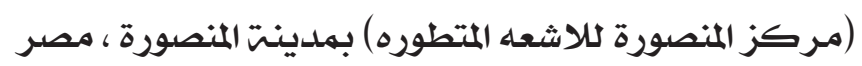
تم تصوير المرضى من قبل اثنين من اجهزه CT المختلفه باستخدام اثنين من تقنئيات إعادة

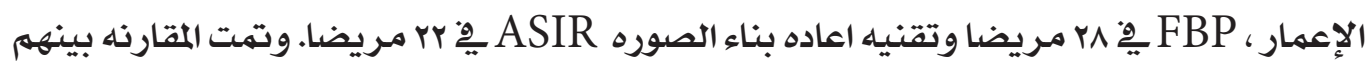

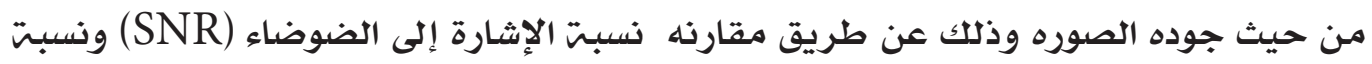

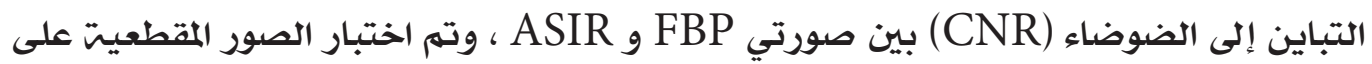

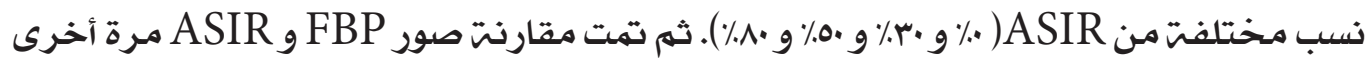

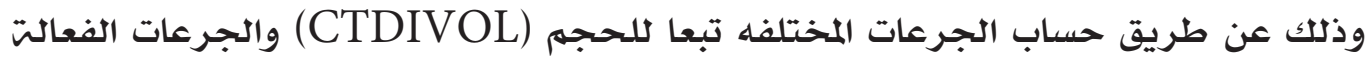

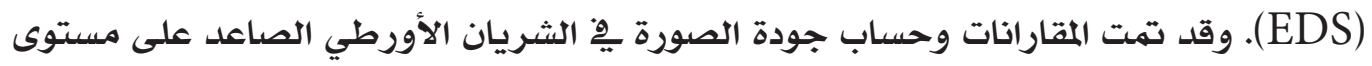
كارينا. وقمنا باستخدام الاحصاء لمقارنه البيانات الناتجه باستخدام التقنيتين

\section{نتائج البحث}

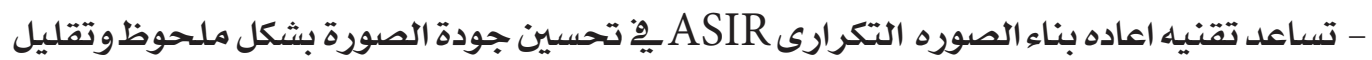

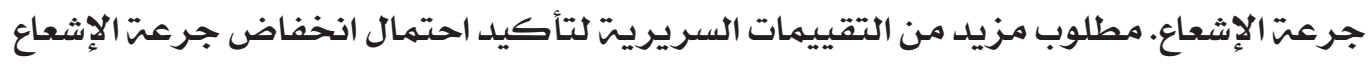

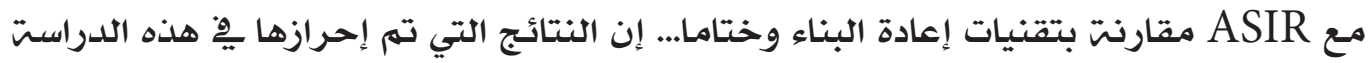
يمكن الاستفادة منها يِّ دراسات بحثيتة قادمتة. 
